\title{
Antología del pensamiento crítico costarricense contemporáneo
}

Coordinadores

Montserrat Sagot y David Díaz Arias

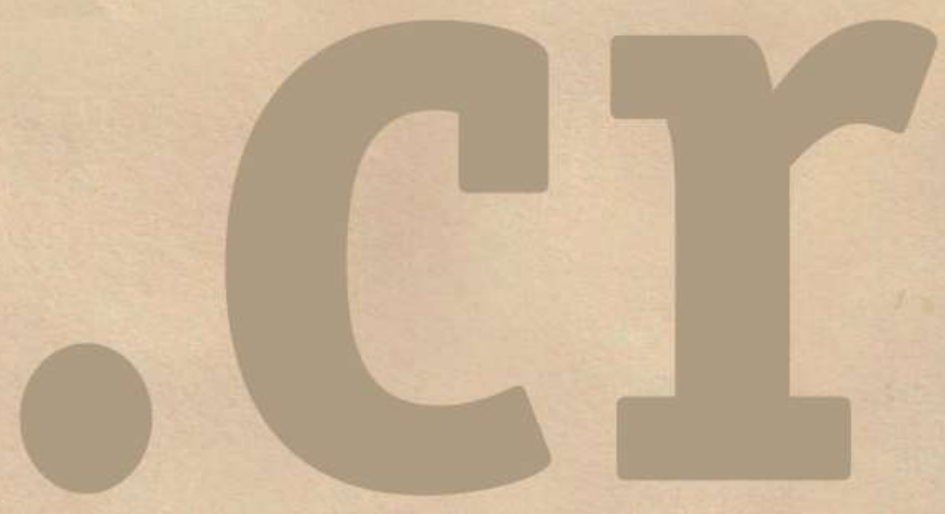

Colección Antologías del Pensamiento Social Latinoamericano y Caribeño 


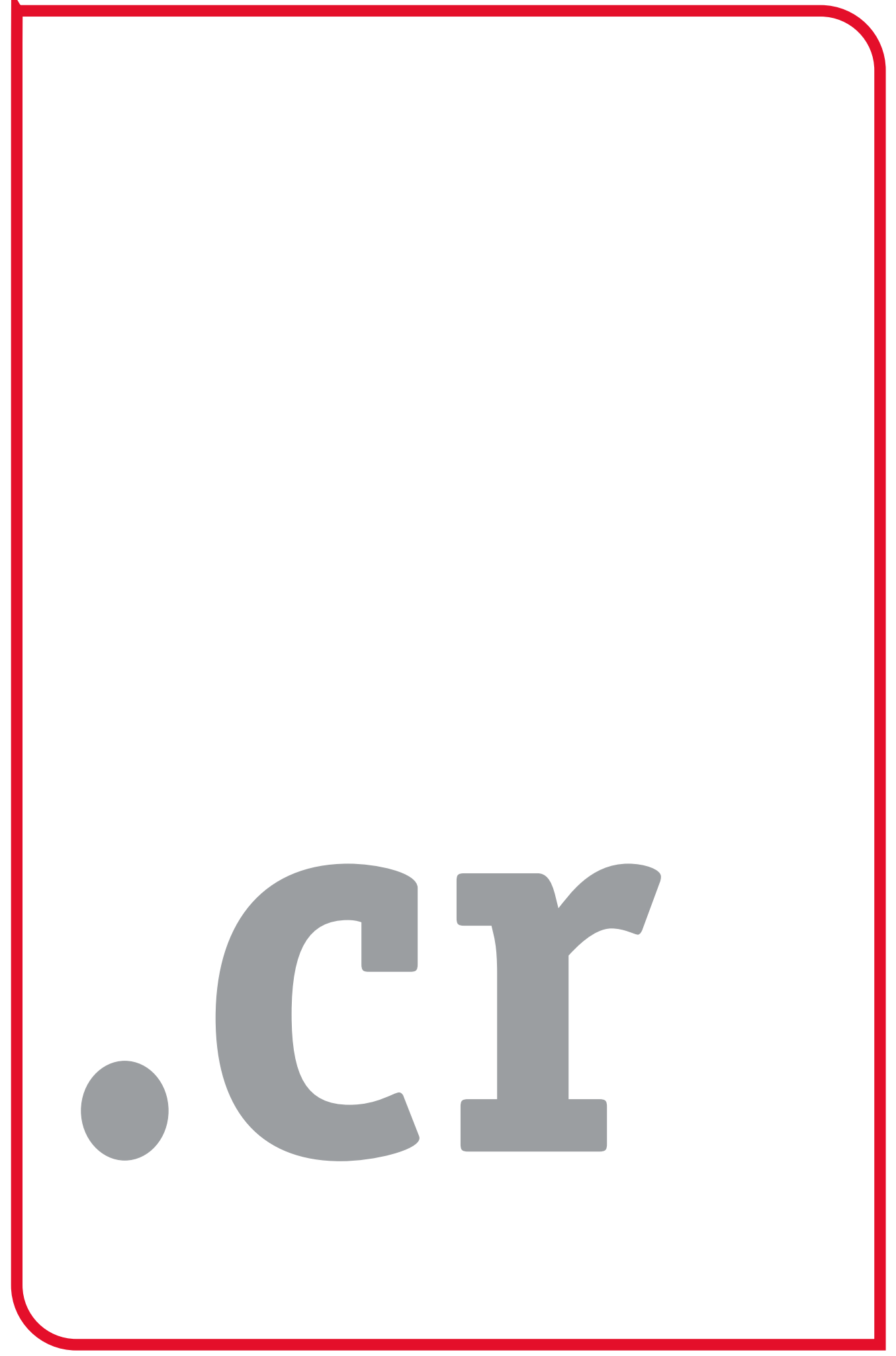





\section{Antología del pensamiento crítico costarricense contemporáneo}

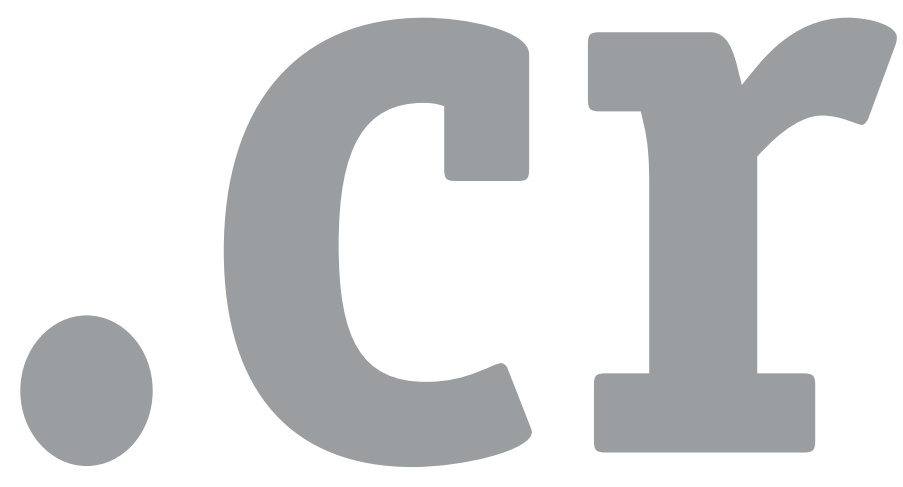


Antología del pensamiento crítico costarricense contemporáneo / Joaquín García Monge ... [et al.] ; compilado por Montserrat Sagot y David Díaz Arias. - 1a ed . - Ciudad Autónoma de Buenos Aires:

CLACSO, 2019.

Libro digital, PDF - (Antologías del pensamiento social latinoamericano y caribeño)

Archivo Digital: descarga y online

ISBN 978-987-722-557-0

1. Sociología. 2. Pensamiento Crítico. 3. Costa Rica. I. García Monge, Joaquín. II. Sagot, Montserrat, comp. III. David Díaz Arias, comp.

CDD 301.097286

Otros descriptores asignados por CLACSO:

Pensamiento Crítico / Emancipación / Colonialidad / Costa Rica /

América Latina 


\section{Antología del pensamiento crítico costarricense}

contemporáneo

\section{Coordinadores}

\section{Montserrat Sagot}

\section{David Díaz Arias}

Joaquín García Monge I Manuel Mora Valverde I Víctor Hugo Acuña Ortega | Carlos Sandoval García I Alexander Jiménez Matarrita I José María Gutiérrez Gutiérrez I Carmen Lyra I Yolanda Oreamuno Unger | Rodrigo Facio Brenes | Rodolfo Cerdas Cruz | Manuel A. Solís Avendaño | Mercedes Muñoz Guillén | Jorge Rovira Más I Ciska Raventós Vorst I Carlos Luis Fallas Sibaja I Daniel Camacho Monge I Eugenia Rodríguez Sáenz | Carlos Sojo I Juliana Martínez Franzoni I Diego Sánchez-Ancochea I Quince Duncan I Omar Hernández Cruz | Eugenia Ibarra Rojas I Juan Rafael Quesada Camacho I Helio Gallardo I Mónica Pérez Granados I Yadira Calvo Fajardo | Ana Sojo I Alda Facio Montejo I Ana Carcedo I Gabriela Arguedas Ramírez

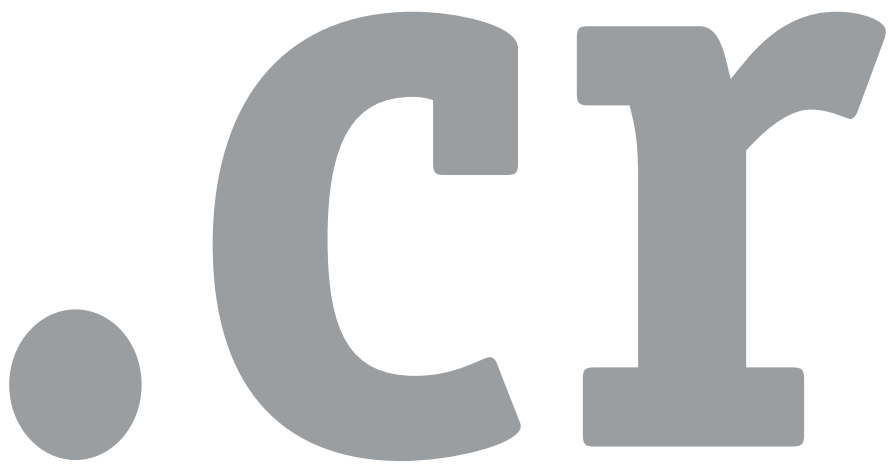

Colección Antologías del Pensamiento Social Latinoamericano y Caribeño 


\section{CLACSO}

Consejo Latinoamericano

de Ciencias Sociales

Conselho Latino-americano

de Ciências Sociais

Colección Antologías del Pensamiento Social Latinoamericano y Caribeño

Directores de la colección - Karina Batthyány y Pablo Gentili

\section{CLACSO - Secretaría Ejecutiva}

Karina Batthyány - Secretaria Ejecutiva

Nicolás Arata - Director de Formación y Producción Editorial

Lucas Sablich - Coordinador Editorial

\section{LIBRERÍA LATINOAMERICANA Y CARIBEÑA DE CIENCIAS SOCIALES CONOCIMIENTO ABIERTO, CONOCIMIENTO LIBRE}

Los libros de CLACSO pueden descargarse libremente en formato digital o adquirirse en versión impresa desde cualquier lugar del mundo ingresando a www.clacso.org.ar/libreria-latinoamericana

Antología del pensamiento crítico costarricense contemporáneo (Buenos Aires: CLACSO, diciembre de 2019) ISBN 978-987-722-557-0

(c) Consejo Latinoamericano de Ciencias Sociales I Queda hecho el depósito que establece la Ley 11723.

No se permite la reproducción total o parcial de este libro, ni su almacenamiento en un sistema informático, ni su transmisión en cualquier forma o por cualquier medio electrónico, mecánico, fotocopia u otros métodos, sin el permiso previo del editor. La responsabilidad por las opiniones expresadas en los libros, artículos, estudios y otras colaboraciones incumbe exclusivamente a los autores firmantes, y su publicación no necesariamente refleja los puntos de vista de la Secretaría Ejecutiva de CLACSO.

\section{CLACSO}

\section{Consejo Latinoamericano de Ciencias Sociales - Conselho Latino-americano de Ciências Sociais}

Estados Unidos 1168 I C1023AAB Ciudad de Buenos Aires I Argentina

Tel [54 11] 43049145 I Fax [54 11] 43050875 I <clacso@clacsoinst.edu.ar> I <www.clacso.org>

Patrocinado por la Agencia Sueca de Desarrollo Internacional Asdi 


\section{ÍNDICE}

Montserrat Sagot y David Díaz Arias

Presentación

\section{CRÍTICA AL MITO DE LA IDENTIDAD NACIONAL COSTARRICENSE}

\section{Joaquín García Monge}

Ante el Monumento Nacional (1921)

\section{Manuel Mora Valverde}

Por la afirmación de nuestra democracia. Por el progreso y bienestar de nuestra nación (1938)

\section{Víctor Hugo Acuña Ortega}

La invención de la diferencia costarricense, 1810-1870 (2002)

\section{Carlos Sandoval García}

El otro nicaragüense en el imaginario colectivo costarricense.

Algunos retos analíticos y políticos (2002)

\section{Alexander Jiménez Matarrita \\ Países inhóspitos, países hospitalarios (o de cómo imaginamos el lugar de los inmigrantes en Costa Rica) (2005)}


José María Gutiérrez

La importancia de la generación endógena de conocimiento científico en Costa Rica (2011)

\section{CRÍTICA AL MITO DE LA DEMOCRACIA COSTARRICENSE}

\section{Carmen Lyra}

El grano de oro y el peón (1933)

Yolanda Oreamuno Unger

El ambiente tico y los mitos tropicales (1939)

\section{Rodrigo Facio Brenes}

Acto de clausura del año académico de 1954 (1954)

Rodolfo Cerdas Cruz

Democracia liberal (1978)

Manuel A. Solís Avendaño

El 48 como desborde trágico (2007-2008)

\section{Mercedes Muñoz Guillén}

Costa Rica: la abolición del ejército y la construcción

de la paz regional (2014)

Jorge Rovira Más

El nuevo estilo nacional de desarrollo (1995)

Ciska Raventós Vorst

El No en perspectiva (2018)

\section{CRÍTICA AL MITO DE LA IGUALDAD Y LA PAZ}

\section{Carlos Luis Fallas Sibaja}

La gran huelga bananera del Atlántico de 1934 (1955)

\section{Daniel Camacho Monge}

Interpretaciones teóricas de la sociedad latinoamericana (1974)

\section{Eugenia Rodríguez Sáenz}

¿Víctimas inocentes o codelincuentes? Crimen juvenil y abuso sexual en Costa Rica en los siglos XIX y XX (2005)

\section{Carlos Sojo}

La igualdad imaginada (2010) 


\title{
EL NUEVO ESTILO NACIONAL DE DESARROLLO
}

\author{
Jorge Rovira Más
}

\section{INTRODUCCIÓN}

A partir de 1983, Costa Rica ha estado viviendo un proceso de transición entre lo que fue su viejo estilo nacional de desarrollo, el que empezó configurarse en 1948 y tuvo vigencia hasta 1980, por un lado, y el nuevo que apenas comienza a decantarse. La profunda crisis económica de los años 1980-1982 significó, por así decirlo, el parteaguas que ha venido a demarcar dos etapas diferentes en la evolución de la sociedad costarricense. ${ }^{1}$

La transición en curso constituye un proceso de cambio de la estructura social, que no solo es más intenso de lo que a primera vista suele pensarse, sino que está sentando, con alguna prisa y en todo caso sin pausa, las bases de una Costa Rica diferente.

Como todo proceso de modificación de la estructura social, es asincrónico, es decir, no todas las áreas institucionales de la sociedad cambian en la misma dirección ni lo hacen con la misma velocidad. Por otra parte, las transformaciones ocurren en las distintas

1 Para un examen detallado de la noción de "estilo nacional de desarrollo" que sirve de fundamento a este análisis, puede consultarse, además de lo que se expondrá aquí, el artículo de Jorge Graciarena (1976) "Poder y estilos de desarrollo. Una perspectiva heterodoxa”. Un uso amplio de este concepto para la descripción del caso de Costa Rica, lo realizamos en nuestro libro Costa Rica en los años ochenta (1987). 
dimensiones en que puede ser descompuesta, para fines analíticos, la estructura social: en la organización social (el mundo de los valores y los patrones de comportamiento); en la morfología social (en los grupos sociales); y en la dimensión psicosocial (los valores y las normas ya internalizados por los individuos como contenidos psíquicos). ${ }^{2} \mathrm{En}$ este artículo, vamos a presentar lo que nos parece que son algunos de los rasgos emergentes del nuevo estilo nacional de desarrollo que está empezando a constituirse en Costa Rica. Previamente, precisaremos el significado de lo que entendemos por esta noción y señalaremos las características que patentiza el caso costarricense durante el lapso que va de 1950 a 1980.

\section{EL ESTILO NACIONAL DE DESARROLLO DE 1948-1980: DESARROLLO ECONÓMICO SOCIALMENTE ORIENTADO}

Empecemos por recordar que la noción de "estilo de desarrollo" no es equivalente a las de "patrón de desarrollo" o "modelo de desarrollo". Con estas últimas se alude en general a la forma como se interrelacionan ciertas variables consideradas como primordiales (a menudo únicamente desde el punto de vista económico), lo que hace posible que pueda hablarse, por ejemplo, del "patrón de desarrollo de América Latina en la Posguerra", o también de la crisis del modelo de sustitución de importaciones de Centro América".

Pero la idea de "estilo de desarrollo" lo que persigue es aprehender sucintamente y de un modo comprensivo la manera concreta como una sociedad particular ha evolucionado o se mueve durante un lapso histórico. Inherentes a su contenido, al menos en la versión crítica de Graciarena aquí adoptada, son los siguientes elementos. En primer lugar, el estilo de desarrollo es lo que hemos denominado en otra parte, recurriendo a una analogía con algunos conceptos físicos propios de la Mecánica, como "una resultante histórica" (Rovira Mas, 1987: 17). Es decir, "es lo que se sedimenta en la práctica política y social, luego de la confrontación siempre conflictiva [de una determinada estrategia de desarrollo; J.R.M.] con las otras alternativas posibles (y a veces parcial o potencialmente factibles) que orientan las presiones de los sectores o grupos sociales" (Graciarena, 1976: 192). Consecuentemente, la manera concreta como se mueve una sociedad en el transcurso de un período particular, no es el fruto únicamente (excepto en situaciones límites, sobre todo bajo regímenes políticos autoritarios

2 Para un examen detenido de estos conceptos, puede recurrirse a la obra seminal de Gino Germani (1979) Política y sociedad en una época de transición, en particular el capítulo I de la primera parte, titulado "La estructura social y el análisis del cambio", pp. 19-63. 
de derecha o de izquierda) de los grupos sociales que patrocinan una estrategia de desarrollo específica y por completo hegemónica; constituye más bien el fruto que se va decantando (a manera de valores que se difunden y de prácticas que cobran vida institucional) de la interacción entre distintas estrategias, proyectos políticos y planteos en defensa de intereses sectoriales, los que son promovidos por grupos sociales que cuentan con recursos de poder con peso diferenciado en la escena política. Es claro entonces que la forma como la sociedad se va moldeando, se ve influida no solo por aquellas estrategias cuyos agentes portadores disponen de más recursos de poder que otros actores políticos (y que por ello mismo pueden convertir sus orientaciones en dominantes), sino también por las resistencias que a los proyectos o a las estrategias dominantes oponen múltiples actores. Esto es tanto más así cuanto más democrática sea una sociedad. En segundo lugar, es por esta razón que Graciarena (1976: 189) insiste en "la centralidad estratégica del conflicto como atributo de un estilo". Por último, parece conveniente insistir en que "el estilo no es un producto del azar ni tampoco de la "lógica de la historia", ni de "condicionamientos estructurales" que operan ciega e inexorablemente. No lo es porque tiene sangre y carne (individuos y grupos) así como una voluntad social y política que actúa en cierta dimensión histórica y se orienta por ideologías [...] En una situación nacional históricamente concreta y condicionada, hay siempre más de una opción posible" (Graciarena, 1976: 187).Puntualizado lo anterior, vale la pena tratar de identificar con brevedad el estilo nacional de desarrollo de Costa Rica a lo largo de 1948-1980. Esto nos facilitará luego, por la vía del contraste, aproximarnos a una caracterización muy provisional del nuevo estilo en proceso de sedimentación.

En efecto, en un contexto económico internacional expansivo de largo aliento como fueron los años inmediatamente posteriores a la Segunda Guerra Mundial, caracterizado entre otras cosas por la exportación de capital llevada a cabo por las corporaciones transnacionales hacia América Latina, con el fin de invertir prioritariamente en el sector industrial de estas economías; con este trasfondo, internamente, en Costa Rica, se fue convirtiendo en hegemónico un proyecto político impulsado por una alianza de fuerzas sociales, las cuales emergieron con perfil propio al primer plano de la escena política tras el movimiento armado encabezado por José Figueres en 1948. Entre este año y 1970, primero, la paulatina materialización de este proyecto político enfrentó las resistencias que le opusieron, principalmente aunque no de modo exclusivo, los sectores empresariales ligados a la agroexportación de vieja data y al comercio importador, con el resultado de que cada cuatro años vio morigerado su paso, debido 
a la conocida alternabilidad que se presentó en el acceso al Poder Ejecutivo por los principales partidos políticos o coaliciones de ellos. Esta circunstancia se vio alterada en la década de los setentas cuando el Partido Liberación Nacional (PLN), por haber ostentado durante ocho años consecutivos una buena porción de los más importantes recursos de poder de nuestra sociedad (dado su persistente control del Ejecutivo entre 1970-1978 y por su concomitante y tradicional mayoría de diputados en la Asamblea Legislativa, además de su influencia decisiva sobre las instituciones autónomas), logró profundizar -y, diríamos, acentuar- la concreción de algunos de los componentes o características de su proyecto político. No es ocioso destacar que la tensión que se produjo entre estos dos mayoritarios aglutinamientos políticos (el PLN y la oposición coligada), representó La expresión no solo de intereses sociales diferentes sino también de planteamientos ideológico-programáticos claramente divergentes. El desigual ritmo alcanzado en la concreción del estilo nacional de desarrollo en esos dos períodos (1948-1970 y 1970-1980) en virtud de las circunstancias antedichas, constituye un aspecto primordial en su aprehensión.

Las consecuencias derivadas de esta constelación de factores, fueron las siguientes: crecimiento económico sostenido y con tasas elevadas (del orden del 6\% anual en términos reales como promedio); diversificación y modernización capitalista del aparato productivo, aunque con escasa generación interna de tecnología y pocos logros en cuanto a los niveles de integración entre las ramas y los sectores, aspecto que no se vio mejorado significativamente con el tipo de industrialización emprendida en el marco del Mercado Común Centroamericano (MCCA). Pero este crecimiento económico se acompañó asimismo de una dinámica de distribución del ingreso de naturaleza "mesocrática", ${ }^{3}$ que hizo progresar la posición de los grupos de perceptores de rentas medias. Por otra parte, surgieron y se consolidaron sectores empresariales de nueva laya, bien aquellos vinculados a los nuevos rubros de exportación (azúcar y carne de ganado vacuno, industria), bien los orientados a atender la creciente y más variada demanda interna; y de igual modo, la estructura socioocupacional cobró un perfil menos tradicional gracias a la aparición de los asalariados del sector industrial y con la sobresaliente expansión experimentada por la burocracia del sector público. El papel del Estado, dada la ampliación de sus funciones económicas (tanto por su labor en la creación de la infraestructura requerida por el capital privado, así como por sus múltiples acciones reguladoras del mercado y por sus excesos

3 Véase también sobre este punto el trabajo de Jorge Graciarena (1976) "Tipos de concentración del ingreso y estilos políticos en América Latina". 
intervencionistas en el ámbito de la producción directa, como sucedió en el caso de CODESA), al igual que por sus actuaciones en el ámbito de la redistribución del ingreso y de la política social en general, resultó fundamental a lo largo de estos años. A su vez, la legitimidad del sistema político y de su régimen de democracia representativa, se consolidó paso a paso en cada una de las tres décadas transcurridas entre 1950 y 1980 . A ello concurrieron los cambios institucionales efectuados tras la guerra civil de 1948, la difusión y la internalización de valores y normas más ajustadas a una cultura política democrática plenamente moderna, y la eficacia de los gobiernos en el mejoramiento de las condiciones de vida de amplios grupos de la población. Por último, en el terreno de la educación, a dos décadas (1950-1970) de apoyo repetido a la expansión cuantitativa de los establecimientos de segunda enseñanza y a una menos inequitativa distribución geográfica de ellos por parte de los gobiernos, le sucedió la extensión notable de la educación superior, tanto en lo concerniente al número de universidades (pasándose de una en 1970 a 5 en 1980, cuatro públicas y una privada), como en lo relativo al número de estudiantes de diferentes estratos socioeconómicos que accedieron a ellas.

En suma, que si con pocas palabras resultara obligante calificar a este estilo de desarrollo, no podríamos menos que recurrir al señalamiento sucinto de que su nota distintiva fue la de orientarse al crecimiento económico pero con persistentes tendencias a reducir la desigualdad social y a conformar una sociedad mucho menos polarizada que la precedente en la historia del país, con un mayor número de oportunidades para un mayor número de costarricenses. O, si se quisiese apelar a la fórmula breve del distinguido sociólogo Eugenio Fonseca Torios, anterior a la actualmente de moda aunque patrocinada desde hace algunos años por la CEPAL ("desarrollo con equidad"), diríamos que se trató de "un desarrollo económico socialmente orientado". ${ }^{4}$

\section{EL NUEVO ESTILO NACIONAL DE DESARROLLO: ANTICIPACIONES PROVISIONALES}

Líneas arriba indicamos que la severa crisis económica de 1980-1982 ha venido a representar un mojón divisorio entre dos etapas históri-

4 Esta fórmula la utilizó sistemáticamente Eugenio Fonseca Tortós en sus escritos en los que reconocía explícitamente que sus valores personales lo comprometían con un desarrollo económico socialmente orientado. Véanse, entre otros, los siguientes trabajos: "Democracia e igualdad de oportunidades" (1952: 51-58); "Estratificación social y desarrollo. Reflexiones, sugerencias y preguntas para investigaciones futuras" (1968); y "La comunicación colectiva, la manipulación como forma de poder y la formación de opinión pública: Un caso concreto en Costa Rica” (1973: 35-63). 
cas de la vida nacional, un parteaguas entre dos estilos de desarrollo, cada uno ofreciendo un conjunto de características que tienden a ser un tanto distintas. Y señalamos igualmente que a partir de 1983 hemos estado viviendo un período de transición entre ambos estilos, que como tal incluye la persistencia de muchos de los rasgos de la vieja estructura social y la emergencia de las características de la nueva, todo ello en un proceso complejo de pugna entre valores y prácticas sociales en declinio pero que se resisten a dejar de tener vigencia, y otros valores y prácticas que no sin dificultad propenden a instalarse en la vida nacional de una manera generalizada.

Empecemos a continuación por retomar lo que constituye un tópico, un lugar común, aunque no por ello carezca de significación e importancia para nuestros propósitos de aproximarnos al nuevo estilo nacional de desarrollo que parece estarse configurando en Costa Rica. Empecemos, pues, por recordar que la economía mundial se encuentra experimentando un lento y tortuoso proceso de reestructuración global, el cual se inició desde hace algunos años y en la actualidad se encuentra en plena marcha, acicateado aún más y con perfiles inesperados por los acontecimientos políticos recientes advenidos en los países europeos del llamado "socialismo real". La búsqueda de una economía internacional mucho más abierta, con menores restricciones al intercambio de mercancías y ahora también de servicios, en la que se están forjando grandes bloques económicos y apareciendo otras naciones líderes, son algunos de sus componentes. El resultado final será una diferente división internacional del trabajo respecto de la que emergió luego de que concluyera la Segunda Guerra Mundial y que prevaleció hasta los años setenta. En su seno, "la guerra económica pacífica" basada en la investigación científica y en el desarrollo de productos tecnológicamente más elaborados, en la competitividad dentro de fronteras económicas ensanchadas, será el motor decisivo de la producción y el comercio capitalista cada vez más en una escala planetaria. Organismos internacionales como el Banco Mundial (BM), el Fondo Monetario Internacional (FMI) y el Acuerdo General sobre Aranceles y Comercio (GATT) en un plano mundial; el Banco Interamericano de Desarrollo y la Agencia para el Desarrollo Internacional (AID) de los Estados Unidos, estos dos con influencia especial en América Latina (la AID con incidencia particular, dentro de América Latina, en Centroamérica y el Caribe), son algunas de las entidades patrocinadoras, con una perspectiva global, de este nuevo orden económico internacional. Evidentemente, Costa Rica llegará también a ocupar un sitio determinado en la nueva división internacional del trabajo en tránsito de constituirse, y su modo de inserción en ella es lo que se está jugando y definiendo en estos años. 
Pero este nuevo orden económico internacional y su inherente división internacional del trabajo, no podrá llegar a ser tal si no es a través de los cambios y las transformaciones a las que se encuentran sometidas las economías nacionales, las de los países grandes y las de los pequeños, las de los débiles y las de los poderosos. Y estas modificaciones de la estructura económico-social de los países, no ocurren como un efecto inmediato inducido desde afuera. En realidad, todas las líneas de fuerza o de influencia que vienen del exterior a través de múltiples canales y que se orientan a alterar la situación interna para ajustarla al nuevo orden económico mundial que las naciones más influyentes procuran plasmar; estas líneas de fuerza, se ven sometidas a un procesamiento interno de innegable filiación política. Y esto es tanto más así cuanto más democrática sea una sociedad, cuanto más pluralista lo sea. En otras palabras, cualquier "modelo de desarrollo" que se persiga introducir en Costa Rica, cualquier "patrón de ajuste estructural" que se intente implementar en nuestro país, se verá inevitablemente modificado y alterado por la manera como las distintas fuerzas políticas internas lo vayan procesando, bien avalándolo en forma completa, bien matizando sus pretensiones, bien resistiendo de manera abierta y firme sus alcances. Y es precisamente este derrotero sinuoso y harto complejo lo que conduce al decantamiento del estilo de desarrollo, que no es sino lo que se concreta efectivamente a partir de la confrontación de tas alternativas de desarrollo esgrimidas por múltiples actores. Su consecuencia es la sedimentación de diferentes valores y prácticas institucionales, más allá de las pretensiones de un solo sector sociopolítico de imponer por completo su propio proyecto o aquel del que se convierta en portador.

Pero si esto es así, si nuestro planteo es heurísticamente fecundo, ¿cuáles serían los fenómenos sociopolíticos más relevantes en la Costa Rica de los años ochenta a los que habría que prestarles la debida atención para intentar aprehender la dirección y el ritmo, el tempo, del nuevo estilo nacional de desarrollo? En primer lugar, es forzoso reparar en el surgimiento, a lo largo de los años ochenta, de una inequívoca bipolaridad en el sistema de partidos políticos, ${ }^{5}$ con un alineamiento de los sectores empresariales y con una base social semejante en cada caso. A partir de 1982, con la creación de las condiciones legales y políticas requeridas para la fundación del Partido Unidad Social Cristiana (PUSC), la vida política nacional ha quedado aherrojada entre estas dos agrupaciones mayoritarias: el PLN y el PUSC. Y a diferencia de lo acontecido en el período 1950-1980, durante el cual

5 Sobre este particular, véase nuestro artículo "Costa Rica: Elecciones, partidos políticos y régimen democrático”, (1990: 44-60). 
las divergencias ideológico-programáticas entre el PLN y la oposición coligada fueron sustantivas, en la. década pasada hemos sido testigos de una acrecida aproximación de ambos partidos en sus propuestas ideológicas y en sus programas de gobierno, lo que se ha tomado aún más claro entre 1986 y $1990 .{ }^{6}$ En otra parte (Rovira Mas, 1990: 52-60) hemos presentado detalladamente dicha convergencia programática tanto en el ámbito de los objetivos cuanto en el de los medios e instrumentos a ponerse en práctica, por lo que no entraremos aquí en pormenores. Mencionaremos apenas que la reestructuración de la economía con vistas a posibilitar que la lógica del mercado pueda funcionar mucho menos regulada o constreñidamente de como lo hizo en el pasado, incluyéndose aquí una mayor apertura al exterior; una economía mixta fuertemente dirigida hacia la exportación para mercados allende la región centroamericana; amplia e incontrolada aceptación del capital extranjero y garantías para su operación; la modernización y la actualización del Estado, lo que implica también no solo privatización sino igualmente desmonopolización de algunas actividades económicas; el apoyo a un nuevo sector productivo, por algunos denominado de "propiedad social"; la transformación del régimen municipal y una política exterior activa y comprometida con ciertos valores como la paz, los derechos humanos y la democracia, son algunos de los elementos fuertemente preconizados por ambos partidos políticos. Debe destacarse, sin embargo, que todo esto no entraña que no existan diferencias entre estas agrupaciones: no solo en cuanto a la cantidad y a la calidad de la tecnocracia disponible en cada caso (el PLN cuenta con más recursos de esta naturaleza y con más experiencia en la gestión del Estado), sino también en un aspecto adicional que puede a la postre resultar decisivo para aprehender el estilo de desarrollo. Nos referimos al ritmo con el cual se persiguen llevar a cabo las modificaciones de la estructura socioeconómica. En el caso del PUSC, existe una proclividad manifiesta a apurar mucho más el paso en relación con los cambios percibidos como necesarios; el gradualismo, en cambio, es nota distintiva del PLN.

Un segundo fenómeno a ser destacado aunque sea de una manera muy gruesa, consiste en la emergencia, en estos años ochenta, de nuevos actores sociopolíticos. Se trata de grupos como los campesinos, las comunidades organizadas, las asociaciones que luchan por

6 Las causas de esta convergencia han sido fundamentalmente las siguientes: la reacción frente a la crisis económica nacional de 1930-1982, el clima de zozobra que despertó en los partidos mayoritarios y en sus dirigencias la situación política de América Central, en especial la Revolución Sandinista; y el acicate que ha entrañado el financiamiento aportado por el Gobierno de los Estados Unidos para encarar, de una cierta manera, las dificultades económicas del país. 
la obtención de vivienda, las organizaciones que trabajan sobre "la cuestión ecológica”, los grupos de mujeres organizadas y otros más que, dadas las características del régimen democrático costarricense y de su pluralismo creciente, exigen atención a sus planteamientos. Desde nuestra óptica, su mayor significación reside en su capacidad para presentar resistencias a las estrategias de desarrollo económico que disponen de mayores recursos de poder en su pretensión de materializarse, logrando con ello moderar el impulso de tales estrategias o en todo caso exigir que se tomen en cuenta demandas y aspiraciones de grupos sociales que hasta ahora al menos han contado con escasa representación dentro de los principales partidos políticos. Se trata en breve del fenómeno caracterizado por algunos autores como de emergencia de "nuevas ciudadanías". ${ }^{7}$ El comportamiento de estos actores tiene que ser tomado en cuenta en cualquier análisis, junto con la actuación igualmente importante, si no más, que despliegan aquellos grupos sociales que se beneficiaron grandemente con el viejo estilo de desarrollo y que ahora resisten los embates que procuran modificar su antigua posición. El caso aquí más evidente es el de la burocracia del sector público.

A la luz de los anteriores elementos, un acercamiento provisional al nuevo estilo nacional de desarrollo, a la dirección global que sigue y al ritmo con el cual la misma se está concretando, nos obliga a realizar los siguientes comentarios. En primer lugar, su orientación general es fruto de proyectos políticos y de planteamientos programáticos en tomo a los cuales existe una gran coincidencia entre las principales fuerzas políticas de la sociedad costarricense, circunstancia que no se encuentra con facilidad en muchas otras partes de la América Latina de nuestros días y que, como ya lo apuntamos, tampoco fue la tónica prevaleciente en Costa Rica durante el período 1950-1980. Esto es lo que quizás explicaría, por lo menos en cierta medida, el éxito que se ha atribuido al proceso de estabilización y al ajuste estructural puesto en marcha en la economía de nuestro país. En segundo lugar, el ritmo, el tempo del estilo, se ha caracterizado hasta el momento por ocho años (contados a partir de la transición comenzada en 1983 pues en 1982 sí que se adoptaron disposiciones drásticas en un tiempo muy corto), ${ }^{8}$ en los cuales los cambios se han sucedido sin apelarse a medidas violentas y extremadamente severas capaces de producir un efecto de shock en la sociedad. Podría ocurrir, ciertamente, que este ritmo no tan enervante como los que se han puesto en práctica en otras

7 Véase sobre el particular el artículo de Portantiero (1984) "La democratización del Estado".

8 Véase, entre otros, nuestro libro Costa Rica en los años ochenta, pp. 57 y ss. 
latitudes de nuestro continente en esta hora aciaga de las crisis económicas y de los ajustes, se viera modificado en los próximos años en vista de la proclividad ya mencionada del PUSC a acelerar las transformaciones de la estructura socioeconómica. De acontecer dicha aceleración, tendríamos una situación inversa a lo sucedido en el período 1950-1980 en cuanto al ritmo del estilo, aunque no así en lo referente a su dirección: en efecto, mientras que en esos años era el PLN el que llevaba la batuta de la velocidad en su afán por materializar su proyecto político, lo que era refrenado por la oposición coligada; si bien entonces era así, en esta transición que estamos viviendo, aun cuando ambas agrupaciones empujan el estilo en una dirección muy parecida, es ahora el PUSC el que se inclina por acelerar las cosas, mientras que el PLN procura realizar los cambios más acompasadamente. En tercer lugar, en razón de las características del sistema político del país y de una reiterada voluntad en el período de Posguerra (1950-1980) por mejorar las condiciones socioeconómicas de numerosos sectores de la población, se han desarrollado, como parte del juego político interno y de las demandas que plantean los grupos sociales, márgenes de maniobra a primera vista insospechados para enfrentar el ajuste sin dejar de atender demandas provenientes de "los de abajo": el programa de vivienda durante la administración Arias Sánchez es un buen ejemplo de esto que decimos. Para lograrlo, se ha requerido voluntad e imaginación políticas, que no han faltado en el país.

Pasaremos a continuación a señalar, no sin cierta rapidez, algunos aspectos que se han ido decantando en estos ocho años y que podrían ir ya formando parte del nuevo estilo nacional de desarrollo:

En primer término, un crecimiento económico continuado aunque, cierto es, con tasas anuales en términos reales claramente inferiores a lo que fue lo comente en el período 50-80: estamos refiriéndonos a un promedio del orden del $4 \%$ anual, lo cual en modo alguno puede menospreciarse en el contexto mundial y latinoamericano actual. Esto ha permitido mantener tasas de desocupación bastante por debajo de las prevalecientes en nuestro subcontinente.

En segundo término, los alcances en la reestructuración del aparato productivo y en su reorientación, que constituyen un aspecto medular del nuevo estilo, manifiestan los siguientes resultados concretos: se ha vuelto a centrar en la exportación el conjunto de los estímulos económicos (crédito, tipo de cambio, certificados de abono tributario y otros más), especialmente para las exportaciones de productos considerados como no tradicionales (que no sean café, banano, azúcar y carne, entre otras), con lo que efectivamente se ha observado un incremento sostenido en el valor de las exportaciones y en su diversificación. Pero la dirección concreta que lleva este esfuerzo exportador, 
está conduciendo al país a una reinserción en la división internacional del trabajo que no se fundamenta mucho en la generación interna de conocimientos y en su aprovechamiento para exportar bienes con un mayor contenido tecnológico producido en Costa Rica. El proceso vigente de reinserción en la economía mundial, es del tipo más fácil y con un impacto menos integral en el conjunto del aparato productivo a largo plazo: exportación de productos agrícolas gracias al relativamente abundante recurso tierra y a la mano de obra barata en este sector; exportación de productos industriales a terceros mercados (incluyéndose aquí el aporte de las empresas maquiladoras y el de aquellas localizadas en las zonas francas), con una tendencia no bien definida en cuanto a la capacidad del sector de continuar expandiendo sustancialmente la oferta; y el turismo, actividad que ciertamente está experimentando un apreciable crecimiento y cuyas perspectivas son de florecimiento en el mediano plazo. En la industria surgida al calor del MCCA y del ensanchamiento de la demanda nacional, en aquella significativa parte suya que sigue vendiendo para el mercado interno, no se ha llevado a cabo hasta ahora ningún cambio de envergadura que le permita adaptarse a las nuevas condiciones de mayor apertura de la economía nacional con las que este tipo de industria tendrá que enfrentarse de manera despiadada cada año que transcurra. Como se sabe, el ajuste estructural en este sector apenas se halla en cierne. ${ }^{9}$ Esta es la realidad de la situación en cuanto al aparato productivo, más allá de los planteamientos expresados por un grupo de economistas y tecnócratas de ambos partidos mayoritarios, pero cuya influencia se ha demostrado limitada, quienes han insistido en la importancia de realizar un esfuerzo conjunto de largo aliento entre el sector privado y el público. Su objetivo sería el diseñar una estrategia de replanteamiento de nuestro vínculo con la economía mundial, con una perspectiva de largo plazo y en la que se aproveche mucho mejor la calidad de la mano de obra nacional y la capacidad latente de generar internamente tecnología.

En tercer término y en contra de lo que por sentido común pudiera pensarse, lo que suele denominarse como el costo social del ajuste no ha sido tan elevado. De una manera bastante gruesa, habría que indicar que hasta donde los datos y los estudios más recientes lo permiten afirmar, la distribución del ingreso no ha experimentado un desmejoramiento importante. ${ }^{10} \mathrm{Y}$ en cuanto a la pobreza, un estudio

9 Véase en torno a este tema el artículo de Quirós (1990) "El ajuste estructural en la industria".

10 Véase el trabajo de Sauma y Trejos (1990) "Evolución reciente de la distribución del ingreso en Costa Rica: 1977-1986". 
reciente ha indicado "que la incidencia de la pobreza a partir de 1986 probablemente tendió a reducirse o por lo menos a no incrementarse entre 1987 y 1989 . Como estos años concentran los mejores esfuerzos de ajuste estructural, se estaría ante un proceso de ajuste que ha logrado por lo menos no empeorar la situación de los grupos más pobres y que se aproximaría a lo que algunos autores han denominado "ajuste con rostro humano". De nuevo este proceso contrasta con las experiencias vividas por otros países de la región" (Trejos, 1990: 29 y 31). En cuarto lugar, en lo concerniente a los grupos empresariales, acaso lo más novedoso sea el fortalecimiento tanto de aquellos vinculados a la producción no tradicional exportable a terceros mercados como el de los relacionados con las actividades bancadas privadas de reciente aparición; ${ }^{11}$ y se han consolidado varias corporaciones que apenas se iniciaban como tales al finalizar los años setenta, valga decir, corporaciones que cuentan con muchísimo capital y con una acrecida diversificación de sus inversiones (el caso de Lachner \& Sáenz es uno de los más sobresalientes). Otro fenómeno de interés, concomitante con los anteriores, es el papel que empiezan a desempeñar los profesionales jóvenes, con edades que oscilan entre 25 y 35 años, graduados en algunas ramas de la administración o de la ingeniería en la Universidad de Costa Rica o en el Instituto Tecnológico de Costa Rica, pero que cuentan con posgrados en manejo de negocios en algunos de los establecimientos privados de educación superior. Estos jóvenes son los portadores de una nueva manera de hacer negocios en el país y no menos de enfocar la política nacional y de participar en ella, además de ser típicos reproductores y difusores de pautas de estilo de vida importadas que se aproxima a la de los denominados "yuppies" norteamericanos. ${ }^{12}$ En quinto lugar, la reorganización del Estado y sobre todo la redefinición de su papel en el proceso de desarrollo económico, en la política social y en la profundización del régimen democrático del país, es un asunto central sobre lo cual es mucho más

11 De interés sobre este punto es el artículo de Vega (1984) "La recomposición del bloque en el poder en Costa Rica, la política norteamericana y el Fondo Monetario Internacional (1982-1984). Coyuntura y perspectivas".

12 Con el término "yuppie" ("Young Urban Professional People") dentro de la cultura norteamericana, se pretende describir lo siguiente: a adultos jóvenes profesionales muy orientados a ganar dinero y a obtener éxito en el mundo de los negocios; su estilo de vida además refleja un gran interés por estar a la moda en el vestido, en la alimentación, en los enseres domésticos y en los automóviles. Las parejas de "yuppies", con elevadísimos ingresos familiares producto de sus actividades profesionales, tienden además a posponer la paternidad y a interesarse más en colocarse bien en el mercado laboral correspondiente, así como a realizar un tipo de consumo ostentoso y sofisticado (carros europeos, viajes de placer frecuentes, ropa muy cara, etc.). 
lo que se ha debatido que lo concretado. ${ }^{13}$ Esto es comprensible en vista de que lo que se halla en juego es una redemarcación de los límites entre lo público y lo privado, de efectos duraderos para las décadas inmediatamente posteriores. Fuera del lento y dificultoso desmantelamiento de CODESA, que representa una realidad, aquello que posee el más grande significado es la paulatina devolución al mercado y a su lógica organizadora, de un papel y de una posición más protagónica que la que poseyó en la Costa Rica de la Posguerra, cuando poco a poco se fueron estableciendo múltiples regulaciones y controles. La importancia capital de este cambio en curso, radica en que trastoca por completo un valor central del viejo estilo de desarrollo y reorienta la acción social de los individuos en un sinnúmero de ámbitos de la vida colectiva. En otras palabras, la conducta del costarricense estará cada vez más permeada, en las múltiples esferas en las que se desenvuelva, por los valores más típicamente capitalistas: el afán de ganancia y el cálculo de la rentabilidad o del costo-beneficio implicado en las distintas actividades en las que se involucre. Simultáneo con ello, se está difundiendo una exaltación de la empresa privada y de la iniciativa individual, que complementa la idea de la ineficacia e ineficiencia per se del Estado.

En sexto lugar, la legitimidad del sistema político costarricense no ha sufrido mengua alguna. Por el contrario, tal como se ha demostrado, frente a la crisis de eficacia en la gestión gubernamental ocurrida durante la administración Carazo Odio, lo que se tradujo en una pequeña disminución de la legitimidad construida en la Posguerra, los sucesivos gobiernos no solo fueron más eficaces en el manejo de la crisis económica primero y en la administración del Estado después, sino que así fueron percibidos por la ciudadanía, todo lo cual se tradujo en una legitimidad creciente del sistema político (Seligson y Muller, 1907: 301-326). Otro rasgo aquí es la bipolaridad del sistema de partidos ya aludida, la que se ha venido consolidando conforme se avanza en este proceso de transición. Ella trae consigo lo que en otra parte hemos denominado como "el círculo de hierro de los sistemas políticos bipolares". ${ }^{14}$ Una frase de Peeler es muy útil para esclarecer lo que por al entendemos nosotros y las dificultades que confrontan quienes

13 Un esfuerzo valioso con el propósito de clarificar conceptualmente las grandes vertientes de la requerida transformación del Estado en Costa Rica, es el trabajo preparado por la Comisión de Reforma del Estado Costarricense (COREC), Reforma del Estado en Costa Rica (1990).

14 Véase sobre este punto la serie de cuatro artículos que, cuando se iniciaba el último proceso electoral, publicamos bajo el título de "Partidos políticos y campaña electoral", los días 31 de octubre, primero, dos y tres de noviembre de 1989, en el diario La República, página 17 A. 
piensan en la viabilidad de terceros partidos influyentes: "Puntos de vista alternativos permanecen marginales porque a ellos les es negada la posibilidad de obtener el apoyo de las masas. Y no pueden obtener el apoyo de las masas porque nadie los toma seriamente ya que no tienen el apoyo de las masas" (Peeler, 1985). ${ }^{15}$ Complementa todo esto la cada día más perfilada función que están desempeñando los partidos políticos mayoritarios como meras maquinarias a través de las cuales élites políticas rivales se disputan los votos en el mercado electoral, el acceso al poder y los beneficios que de él se derivan.

Por último, vale la pena mencionar aunque sea apenas de paso, el importante papel que está cumpliendo todo el aparato educativo privado (escolar, colegial y universitario), tan acrecentado en estos años, en la transmisión y consecuente socialización de los niños y los adultos en los nuevos valores centrales del estilo de desarrollo.

Esta aproximación provisional a los rasgos más sobresalientes que muestra el nuevo estilo de desarrollo del país, patentiza un cuadro global que podría ser definido, en atención a la brevedad, como de "ajuste con rostro humano", tal como ya se planteó líneas arriba. Nadie debe dudar, en consecuencia, que estamos viviendo un proceso de reestructuración global de la sociedad costarricense, uno de cuyos elementos primordiales lo constituye la reorganización del aparato productivo en una dirección más típicamente capitalista, en donde la lógica del mercado y todo lo que ella entraña va a desempeñar un papel más significativo que en nuestro pasado reciente. Pero debe reconocerse igualmente que al menos hasta el momento el denominado "costo social del ajuste" no ha tenido el impacto corroborable en otras partes del mundo, principalmente de América Latina. Queda por verse si el tránsito en curso permitirá preservar la herencia de un "desarrollo socialmente orientado a largo plazo" (aunque ello sea recurriéndose a procedimientos diferentes a los que prevalecieron durante los años 1950-1980) o si, por el contrario, los valores que han prevalecido en la historia del país en cuanto a la preocupación por no profundizar la desigualdad social y, antes bien, reducirla dentro de un régimen político democrático, carecerán de vigencia en los años por venir.

\section{BIBLIOGRAFÍA}

COREC (1990). Reforma del Estado en Costa Rica. San José: EDICOSTA.

Faletto, E.; Martner, G. (1986). Repensar el futuro. Estilos de desarrollo. Caracas: Editorial Nueva Sociedad UNITAR/PROFAL.

15 La traducción del inglés es nuestra. 
Fonseca T., E. (1962). Democracia e igualdad de oportunidades. Combate . San José: Instituto Internacional de Estudios Políticos-Sociales, pp. 51-58.

Fonseca T., E. (1968). Estratificación social y desarrollo. Reflexiones, sugerencias y preguntas para investigaciones futuras. Ponencia presentada al seminario sobre Sociología del Desarrollo. Río de Janeiro.

Fonseca T., E. (1973). La comunicación colectiva, la manipulación como forma de poder y la formación de opinión pública: Un caso concreto en Costa Rica. Estudios Sociales Centroamericanos $\mathrm{N}^{\circ}$ 4. San José: Imprenta Las Américas, pp. 35-63.

Franco, R.; Leon, A. (1984). Estilos de desarrollo, papel del Estado y estructura social en Costa Rica. Pensamiento Iberoamericano $\mathrm{N}^{\circ}$ 6. Madrid: Instituto de Cooperación Iberoamericana, pp. 63-92.

García H., G. et al. (1990). La deuda social en Costa Rica. San José: Gaudiseños.Germani, G. (1979). Política y sociedad en una época de transición. Buenos Aires: Paidós.

Graciarena, J. (1976). Tipos de concentración del ingreso y estilos políticos en América Latina. Revista de la CEPAL. Santiago de Chile: Naciones Unidas, pp. 203-237.

Graciarena, J. (1976). Poder y estilos de desarrollo. Una perspectiva heterodoxa. Revista de la CEPAL. Santiago de Chile: Naciones Unidas, pp. 175-193.

MIDEPLAN (1983). El deterioro de la condición social de los costarricenses. San José: MIDEPLAN.

Portantiero, J. C. (1984). La democratización del Estado. Pensamiento Iberoamericano $\mathrm{N}^{\circ}$ 5. Madrid: Instituto de Cooperación Iberoamericana, pp. 99-126.

Peeler, J. (1985). Latin American Democracies: Colombia, Costa Rica and Venezuela. Chapel Hill, N. C.: The University of North Carolina Press.

Rovira M., J. (1987). Costa Rica en los años ochenta. San José: Editorial Porvenir.Rovira M., J. (1990) Costa Rica: Elecciones, partidos políticos y régimen democrático. Polémica $\mathrm{N}^{\mathrm{o}} 11$, pp. 44-60.

Sauma, P.; Trejos, J. D. (1990). Evolución reciente de la distribución del ingreso en Costa Rica: 1977-1986. Documento de trabajo $\mathrm{N}^{\circ}$ 132. San José: Instituto de Investigaciones en Ciencias Económicas de la Universidad de Costa Rica. 
Seligson, M.; Muller, E. (1987) Democratic Stability and Economic Crisis: Costa Rica 1978-1983. International Studies Quarterly, Vol. 31, No 3, pp. 301-326.

Spoerer, S. (1980). América Latina. Los desafíos del tiempo fecundo. México: Siglo XXI editores.Trejos, J. D. (1990). Pobreza y política social en Costa Rica. San José: MIDEPLAN, Documento No. 1 del Proyecto Regional para la superación de la pobreza en América Latina.

Ulate, A. (1990). El ajuste estructural en la industria. Semanario Universidad 30 de noviembre de 1990, p. 18.

Vega, M. (1984). La recomposición del bloque en el poder en Costa Rica, la política norteamericana y el Fondo Monetario Internacional (1982-1984). Coyuntura y perspectivas. Anuario de Estudios Centroamericanos Vol. 19. San José: Editorial de la Universidad de Costa Rica, pp. 59-67. 


\section{COLECCIÓN ANTOLOGÍAS DEL PENSAMIENTO SOCIAL LATINOAMERICANO Y CARIBEÑO [COSTA RICA]}

La selección de textos, para una obra como la que aquí presentamos, exige un proceso de toma de decisiones sobre lo que se va a considerar como pensamiento crítico, sobre la temporalidad de la producción y sobre las temáticas que se van a incluir. En esta antología asumimos la definición de pensamiento crítico derivada de las propuestas teóricas de la Escuela de Frankfurt, basadas en la definición de Marx de 1843, como aquel pensamiento que no solo busca entender la sociedad, sino también criticarla y contribuir como un todo, sumándose a las agendas, miradas y aspiraciones de los movimientos sociales contestatarios. Como crítico, además, en el contexto costarricense destacamos aquellos textos que han enfrentado el espejo (a veces espejismo) nacionalista y han brindado formas originales para repensar Costa Rica como país, como sociedad y como cultura.

En términos de la temporalidad, en esta antología se incluyen textos que abarcan un período de cerca de 100 años, iniciando en la década 1920 y terminando con autores y autoras que desarrollan su producción en las primeras décadas del presente siglo. Sobre la escogencia temática, hemos decidido incorporar trabajos que plantean críticas a un conjunto de mitos sobre la homogeneidad, la igualdad y la excepcionalidad costarricense que se han configurado como poderosos mecanismos de control social y político.

La compiladora y el compilador hemos batallado ampliamente sobre la selección que ofrecemos en esta antología. Por eso, debe verse primeramente como un producto de procesos de discusión sobre las características de los textos, su distribución cronológica, sus aportes a las problemáticas que nos planteamos, la originalidad y actividad pionera de sus proponentes y el impacto en las ciencias sociales costarricenses de estos ensayos. No está demás decir que tenemos claro que esta antología y cualquier otra siempre tendrá sus límites, siempre carecerá de otros trabajos importantes y siempre podría ser enriquecida por otras perspectivas.

Sabidos de eso, también tenemos claro que estos textos que hemos escogido representan lo mejor del pensamiento crítico costarricense y que a partir de ellos se han generado polémicas, discusiones y se han inspirado otros investigadores e investigadoras.

De la presentación de Montserrat Sagot y David Díaz Arias
Montserrat Sagot

David Díaz Arias

Joaquín García Monge

Manuel Mora Valverde

Víctor Hugo Acuña Ortega

Carlos Sandoval García

Alexander Jiménez Matarrita

José María Gutiérrez Gutiérrez

Carmen Lyra

Yolanda Oreamuno Unger

Rodrigo Facio Brenes

Rodolfo Cerdas Cruz

Manuel A. Solís Avendaño

Mercedes Muñoz Guillén

Jorge Rovira Más

Ciska Raventós Vorst

Carlos Luis Fallas Sibaja

Daniel Camacho Monge

Eugenia Rodríguez Sáenz

Carlos Sojo

Juliana Martínez Franzoni

Diego Sánchez-Ancochea

Quince Duncan

Omar Hernández Cruz

Eugenia Ibarra Rojas

Juan Rafael Quesada Camacho

Helio Gallardo

Mónica Pérez Granados

Yadira Calvo Fajardo

Ana Sojo

Alda Facio Montejo

Ana Carcedo

Gabriela Arguedas Ramírez

ISBN 978-987-722-557-0

de Desarrollo Internacional

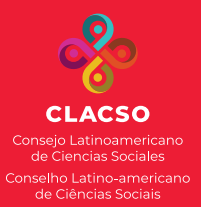

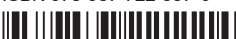

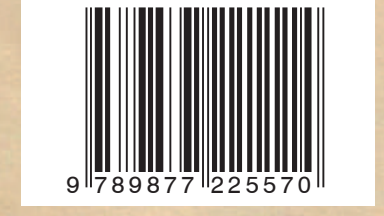

